\title{
Response to Comment on "Gabapentinoid Benefit and Risk Stratification: Mechanisms Over Myth"
}

Heath B. McAnally (D) - Udo Bonnet

Received: November 4, 2020 / Accepted: November 19, 2020 / Published online: February 9, 2021

(c) The Author(s) 2021

Keywords: Addiction; $\quad$ Epidemiology; Gabapentin; Gabapentinoids; Pregabalin; Risk

\section{DIGITAL FEATURES}

This article is published with digital features to facilitate understanding of the article. To view digital features for this article go to https://doi. org/10.6084/m9.figshare.13247177.

H. B. McAnally ( $₫)$

Northern Anesthesia and Pain Medicine, LLC, Eagle River, AK, USA

e-mail: hmcan@uw.edu

H. B. McAnally

Department of Anesthesiology and Pain Medicine, University of Washington School of Medicine, Seattle, WA, USA

\section{U. Bonnet}

Department of Psychiatry, Psychotherapy and Psychosomatic Medicine, Evangelisches Krankenhaus Castrop-Rauxel, Academic Teaching Hospital of the University of Duisburg-Essen, Castrop-Rauxel, Germany

\section{U. Bonnet}

Department of Psychiatry and Psychotherapy, Faculty of Medicine, LVR-Hospital Essen, University of Duisburg-Essen, Essen, Germany

\section{GABAPENTINOIDS: PANACEA OR PANDORA'S BOX?}

We would like to thank Peckham et al. [1] for their critique of our review [2] outlining the benefits and risks of gabapentinoids (GPNs) in the context of general medical, specialty pain management, and addiction medicine practice. Our targeted narrative review of this subject is intended to present a balanced perspective of salient issues to, and ameliorate current confusion regarding the class of drugs among clinicians, pharmacists, and public health workers alike. It seems as though our respondents have grasped our main point, as evidenced by their statement that "When used appropriately under the guidance of healthcare professionals, these represent relatively safe medication options for most patients." Here we would like to make it clear to them and our readership that we also urge caution-with rational and evidence-based benefit:risk stratification-in the prescription of these drugs. In particular, among opioid-dependent persons the risks of both (1) misuse, abuse, and addiction, and (2) physical harm, such as synergistic respiratory depression with other $\mathrm{CO}_{2}$ response-curve shifting agents (e.g., opioids), appear to be elevated.

This article is based on previously conducted studies and does not contain any new studies with human participants or animals performed by any of the authors. 
Association Does Not Equal Causality (or, Innocent Until Proven Guilty)

The issue at hand is whether we rush to summary judgment or proceed with good science toward the elucidation of true risk (or lack thereof) —at both public and individual levels. Due process thankfully has evolved in our civilization, not only in the courtroom but also in the realm of the biological and physical sciences. Attributing agency for dependent outcome $y$ upon independent factor $x$ requires far more than possible cause; the standard must be one of "beyond reasonable doubt."

Toward that end, epidemiology does indeed provide substantial mechanisms for determining causality; the discipline is however far more than the trumpeting of descriptive statistics, which Mark Twain so eloquently disparages for us. It rests upon systematically applied criteria overturning the null hypothesis of no association; as such, the burden of proof falls upon the plaintiff.

Sir Bradford Hill's criteria of causality [3] remain as pertinent today as they did in the previous century and even before. We recognize that many of the criteria await application to the question of whether GPNs are responsible for the alleged adverse outcomes. Nonetheless, let us begin with the consideration of biological plausibility (and coherence).

To be sure, GPNs confer a risk of physical dependence. They certainly display phenomena of tolerance and withdrawal, which both drive physical dependence. However, these phenomena are not dissimilar to other drugs affecting and effecting neural plasticity (such as antidepressants or antipsychotics) or other somatic functions (e.g., proton pump inhibitors and beta-blockers.)

What about psychological/behavioral dependence? GPNs may indeed confer a state of hedonic reward. By the current neurobiologic paradigm, the development of addiction should of course be accompanied by striatal/ventral tegmental area dopaminergism, and although such GPN-mediated mesolimbic phenomena have been refuted by several previous preclinical and clinical studies, one recent study has demonstrated it in a murine model (employing supratherapeutic doses) [4]. While controversial, we allow that GPNs may confer a dose-dependent increase in limbic-region extracellular GABA-ergic activity [5-7], which in vulnerable individuals could indeed lead to "liking", misuse, and abuse and, in some cases, even to "wanting" (to use Berridge and Robinson's wellaccepted framework for addiction) and dependence [8]. And in keeping with the theme of appreciating the increased risk of abuse (with potential addiction) in opioid- or other polysubstance-addicted individuals, GABAergism may "fast-track" (i.e., via "primed circuitry") even weak GABA-mimetic agents such as GPNs to a place of "want" [9]; currently argued to be the decisive (psychological) factor in the development of addiction.

The weight of evidence however favors a more prominent "desensitization" action mediated via inhibition of $\alpha 2 \delta$-subunits of presynaptic voltage-dependent calcium channels (e.g., leading to decreased activity-dependent excitatory neurotransmission), which in essence inhibits the development of addiction's behavioral sensitization $[10,11]$. That is to say, from the laboratory perspective, the GPNs appear to be anti-addictive. Along those lines, even pregabalin (well-accepted as possessing a greater potential for abuse and dependence liability) has been recently shown in a rodent model to confer significant reduction in brain dopamine, glutamate, and norepinephrine [12].

And risks of physical harm? A recent spate of perioperative studies have suggested increased respiratory depression among patients pre-treated with GPNs. In all fairness, however, the postoperative period is a complex one, with residual central nervous system-depressing and $\mathrm{CO}_{2}$ response-blunting activity of halogenated ethers, a potential sympatholytic (and therefore respiratory-drive lowering) effect of local/regional anesthetics, and cumulative exhaustion from physical and psychological stress. GPNs have not yet been shown to shift the $\mathrm{CO}_{2}$ response curve to the right in any consistent fashion [13, 14], and there are too many confounders in the post-anesthesia care unit. One recent prospective study has also suggested that GPN use increases the apnea-hypopnea index (AHI) in older male volunteers [15], although 
the trial only enlisted eight individuals, of whom five also displayed increased AHI with placebo. From the standpoint of plausibility and coherence therefore, there are hardly sufficient data, let alone coherent data, to render a verdict.

Moving on to other criteria, while far from complete, our collective knowledge of the subject at hand to date does not support temporal sequence, consistency, or strength of association/biological gradient, nor has there been ample experimentation. To evaluate the real abuse liability and addictive power of GPNs, prospective clinical studies employing operationalized addiction criteria, collecting precise addiction and other medical history, and utilizing biomarkers (e.g., urine screens) are required.

\section{Who Wants Inflation?}

Causality aside, let's back up and talk strictly about descriptive statistics and scale for a moment. We have no issue with our respondents' claim that "there is significant evidence that these medications are being misused outside of medical recommendations." (In fact we communicated this within the article.) But this is also true of glue among bored/troubled youth, or of mouthwash among severe alcoholics. Epidemiology begins with the identification of a disease cluster, to be sure, but the denominator is of equal if not greater importance: Elmer's ${ }^{\circledR}$ and Listerine ${ }^{\circledR}$ products don't pose major public health problems; and neither Neurontin ${ }^{\circledR}$ (Pfizer Inc., New York, NY, USA) nor Lyrica ${ }^{\circledR}$ (Pfizer Inc.) have convincingly been shown to either in the general population.

Over a denominator of hundreds of millions (perhaps even billions) of prescriptions, psychological dependence on and social impoverishment due to GPNs are not prevalent findings. We (and countless other clinicians involved in the real-world medical management of individuals suffering with chronic pain, psychiatric comorbidities, and 'dual-diagnosis' states comprising substance use disorders and other psychiatric problems, none of which preclude coexisting chronic pain) have not encountered the thousands or even millions of cases of actual addiction to GPNs that are to be expected if this class of drugs indeed possesses significant dependence liability. One of us performed a systematic review [16] on this topic and did not find data remotely supportive of even a fraction of the cases of addiction to be expected from the sheer number of these medications being used by a substantial proportion of the world's population, with an overrepresentation of addictive diatheses, to boot.

Questionable abuse and misuse prevalence estimates have pervaded the literature on the topic, derived from sources such as extrapolation from a (frequently cited) single small internet survey performed by a global market research company [17] and from prescription databases [18]. Pharmacovigilance is outside the scope of our practice, and we do not pretend to possess expert knowledge of the methods involved in arriving at conclusions regarding the population-level dangers of medications. However, as mentioned in the original article, we would like to point out once again that the use of techniques such as Lorenz curves to identify abuse-liable substances should also cast suspicion upon other commonly prescribed medications such as antibiotics [19] and nonsteroidal anti-inflammatory drugs (NSAIDs) [20]. A quarter century ago, using similar modeling methods, triptans were similarly implicated as substances of abuse [21-23]. Inequity of use may indeed represent misuse (or disease clustering) among a small fraction of the population, but it may also represent pharmacokinetic ( \pm pharmacogenomics) heterogeneity, socioeconomic disparities, among others and, in the case of gabapentin proper, the underlying asymptotic active transport curve.

As far as hard outcomes are concerned, the most recent systematic review [24] of clinical and forensic toxicology studies reporting adverse safety outcomes such as impaired driving, overdoses or deaths showed all events on the order of $10^{3}$ (among the studies cited) in association with GPN use. When considering mortality statistics, as pointed out in our article, during a 15-year period (2000-2014) of data collection by the American Association of Poison Control Centers [25], deaths attributed to 
antidepressants $(n>300)$ were two orders of magnitude greater than deaths from GPNs $(n=8)$. A more recent investigation of gabapentin toxicity numbers reported to the U.S. National Poison Data System between 2013 and 2017 identified 17 deaths where gabapentin was involved [26]. While every individual death is a tragedy that may or may not be attributable to GPNs, the question of safety from a public health standpoint again really boils down to a question of scale-the denominator numbers in the hundreds of millions (if not billions) of prescriptions. Furthermore, it should be pointed out again that GPN use/presence in these crosssectional descriptive analyses represents just that: use/presence. Tobacco (and its metabolites) were undoubtedly also present in a substantial fraction of these samples but almost certainly did not comprise the acute/proximate cause of death.

\section{CONCLUSION}

"Knee-jerk" prescription of GPNs in response to a well-intentioned and warranted push toward multimodal and opioid-sparing analgesic regimens has undoubtedly opened the door for misuse, abuse, and even dependence/addiction among many high-risk individuals. The agents are not as benign as perhaps commonly held among clinicians (nor to be fair are NSAIDs or acetaminophen, which pose a significantly greater public health risk in terms of physical morbidity and mortality), and most certainly they are not a panacea. We repeat: evidencebased prescription and cautious monitoring are certainly urged.

Neither however are they the Pandora's box alleged by some. In clinical practice, we counsel patients regarding the individual benefit:risk ratio of medical and surgical interventions. We urge similar rational and evidence-based decision-making at the public health level: the indictment and sentencing of safe pharmacotherapeutic agents with proven benefit $[27,28]$ on the basis of suspicion alone risks causing great harm to hundreds of millions of individuals who are currently benefiting, or who may in the future benefit from appropriate therapy-including indications perhaps heretofore not yet appreciated.

\section{ACKNOWLEDGEMENTS}

Funding. No funding or sponsorship was received for this study or publication of this article.

Authorship. All named authors meet the International Committee of Medical Journal Editors (ICMJE) criteria for authorship for this article, take responsibility for the integrity of the work as a whole, and have given their approval for this version to be published.

Disclosures. Dr Heath McAnally and Dr Udo Bonnet declare that they have no personal, financial, commercial, nor academic conflicts of interest.

Compliance with Ethics Guidelines. This article is based on previously conducted studies and does not contain any new studies with human participants or animals performed by any of the authors.

Peer Review. Please note, contrary to the journal's standard single-blind peer review process, as a commentary this article underwent review by a member of the journal's Editorial Board.

Open Access. This article is licensed under a Creative Commons Attribution-NonCommercial 4.0 International License, which permits any non-commercial use, sharing, adaptation, distribution and reproduction in any medium or format, as long as you give appropriate credit to the original author(s) and the source, provide a link to the Creative Commons licence, and indicate if changes were made. The images or other third party material in this article are included in the article's Creative Commons licence, unless indicated otherwise in a credit line to the material. If material is not included in the article's Creative Commons licence and your intended use is not 
permitted by statutory regulation or exceeds the permitted use, you will need to obtain permission directly from the copyright holder. To view a copy of this licence, visit http:// creativecommons.org/licenses/by-nc/4.0/.

\section{REFERENCES}

1. Peckham AM, Covvey JR, Evoy KE. Letter to the Editor: Comment on "Gabapentinoid benefit and risk stratification: mechanisms over myth". Pain Ther. 2021. https://doi.org/10.1007/s40122-02000222-z.

2. McAnally $\mathrm{H}$, Bonnet U, Kaye AD. Gabapentinoid benefit and risk stratification: mechanisms over myth. Pain Ther. 2020;9:441-52. https://doi.org/10. 1007/s40122-020-00189-X

3. Hill $\mathrm{AB}$. The environment and disease: association or causation? Proc R Soc Med. 1965;58:295-300.

4. Althobaiti YS, Alghorabi A, Alshehri FS, et al. Gabapentin-induced drug-seeking-like behavior: a potential role for the dopaminergic system. Sci Rep. 2020;10(1):10445. https://doi.org/10.1038/s41598020-67318-6.

5. Petroff OA, Hyder F, Rothman DL, Mattson RH. Effects of gabapentin on brain GABA, homocarnosine, and pyrrolidinone in epilepsy patients. Epilepsia. 2000;41(6):675-80.

6. Kuzniecky R, Ho S, Pan J, et al. Modulation of cerebral GABA by topiramate, lamotrigine, and gabapentin in healthy adults. Neurology. 2002;58(3):368-72.

7. Cai K, Nanga RPR, Lisa Lamprou L, et al. The impact of gabapentin administration on brain GABA and glutamate concentrations: a $7 \mathrm{~T}{ }^{1} \mathrm{H}-\mathrm{MRS}$ study. Neuropsychopharmacology. 2012;37(13):2764-71.

8. Berridge $\mathrm{KC}$, Robinson TE. Liking, wanting, and the incentive-sensitization theory of addiction. Am Psychol. 2016;71(8):670-9.

9. Fujita M, Ide S, Ikeda K. Opioid and nondopamine reward circuitry and state-dependent mechanisms. Ann N Y Acad Sci. 2019;1451(1):29-41.

10. Shibasaki M, Kurokawa K, Ohkuma S. Role of alpha2/delta subunit in the development of morphine-induced rewarding effect and behavioral sensitization. Neuroscience. 2009;163(3):731-4.
11. Kurokawa K, Shibasaki M, Mizuno K, Ohkuma S. Gabapentin blocks methamphetamine-induced sensitization and conditioned place preference via inhibition of $\alpha_{2} / \delta-1$ subunits of the voltage-gated calcium channels. Neuroscience. 2011;10(176): 328-35.

12. Taha SHN, Zaghloul HS, Ali AAER, et al. The neurotoxic effect of long-term use of high-dose pregabalin and the role of alpha tocopherol in amelioration: implication of MAPK signaling with oxidative stress and apoptosis. Naunyn Schmiedeberg's Arch Pharmacol. 2020;393:1635-48.

13. Lyndon A, Audrey S, Wells C, et al. Risk to heroin users of polydrug use of pregabalin or gabapentin. Addiction. 2017;112(9):1580-9.

14. Myhre M, Diep LM, Stubhaug A. Pregabalin has analgesic, ventilatory, and cognitive effects in combination with remifentanil. Anesthesiology. 2016;124(1):141-9.

15. Piovezan RD, Kase C, Moizinho R, Tufik S, Poyares D. Gabapentin acutely increases the apnea-hypopnea index in older men: data from a randomized, double-blind, placebo-controlled study. J Sleep Res. 2017;26(2):166-70.

16. Bonnet U, Scherbaum N. How addictive are gabapentin and pregabalin? A systematic review. Eur Neuropsychopharmacol. 2017;27(12):1185-215.

17. Kapil V, Green JL, Le Lait MC, et al. Misuse of the $\gamma$ aminobutyric acid analogues baclofen, gabapentin and pregabalin in the UK. Br J Clin Pharmacol. 2014;78:190-1.

18. Peckham AM, Fairman KA, Sclar DA. Prevalence of gabapentin abuse: comparison with agents with known abuse potential in a commercially insured US population. Clin Drug Investig. 2017;37:763-73.

19. Malo S, José Rabanaque M, Feja C, Jesús Lallana M, Aguilar I, Bjerrum L. High antibiotic consumption: a characterization of heavy users in Spain. Basic Clin Pharmacol Toxicol. 2014;115:231-6.

20. Lallana MJ, Feja C, Aguilar-Palacio I, Malo S, Rabanaque MJ. Use of non-steroidal anti-inflammatory drugs and associated gastroprotection in a cohort of workers. Int $\mathrm{J}$ Environ Res Public Health. 2018;15(9):1836. https://doi.org/10.3390/ ijerph15091836.

21. Hallas J, Støvring H. Templates for analysis of individual-level prescription data. Basic Clin Pharmacol Toxicol. 2006;98(3):260-5.

22. Gaist D, Sindrup SH, Hallas J, Gram LF. Misuse of sumatriptan. Lancet. 1994;344:1090. 
23. Gaist D, Tsiropoulos I, Sindrup SH, et al. Sumatriptan: a population-based study of its use based on interview and prescription register data. Br Med J. 1998;316:1352-3.

24. Hägg S, Jönsson AK, Ahlner J. Current evidence on abuse and misuse of gabapentinoids. Drug Saf. 2020. https://doi.org/10.1007/s40264-020-00985-6.

25. Nelson JC, Spyker DA. Morbidity and mortality associated with medications used in the treatment of depression: an analysis of cases reported to U.S. poison control centers, 2000-2014. Am J Psychiatry. $2017 ; 174: 438-50$.
26. Reynolds K, Kaufman R, Korenoski A, Fennimore L, Shulman J, Lynch M. Trends in gabapentin and baclofen exposures reported to U.S. poison centers. Clin Toxicol. 2020;58(7):763-72.

27. Wiffen PJ, Derry S, Bell RF, et al. Gabapentin for chronic neuropathic pain in adults. Cochrane Database Syst Rev. 2017. https://doi.org/10.1002/ 14651858.CD007938.pub4.

28. Derry S, Bell RF, Straube S, et al. Pregabalin for neuropathic pain in adults. Cochrane Database Syst Rev. 2019;1:CD007076. https://doi.org/10.1002/ 14651858.CD007076.pub3. 